\title{
On the Seismic Jerk
}

\author{
Ramiro Sofronie \\ Independent Technical Expert, Bucharest 030823, Romania
}

\begin{abstract}
The paper deals with the mathematical concept of jerk created in 1825 by Carl Jacobi and introduced in 1936, for applications purposes in dynamics by Aurel A. Beles. Extended in seismic engineering that phenomenon of dynamic amplification is based on the first law of conservation in Mechanics combined with the theory of dislocations developed by Lev Landau. Finally, the two study cases presented in the paper recommend this simply analysis method for advanced practical cases with any degree of accuracy as well as in solving some plausibility inquire as requested by ISO 13822:2010.
\end{abstract}

Key words: Dislocation, earthquake, plausibility, shear, stress concentration.

\section{Introduction}

The paper deals with the dynamic amplification of the transitory motion experienced by the buildings with geometrical irregularities in elevation under their seismic excitation. By the sudden variation of building acceleration, the motion may assume an explosive character. Theoretically, this dynamic phenomenon was first presented by the famous German Scientist Carl Gustav Jacob Jacobi (1804-1851) in his thesis submitted on August 13, 1825 to the University of Berlin for obtaining a doctoral degree in Mathematics. During the following decades of the nineteen century that type of motion was identified in many applications of practical interest, and much later in the Seismic Engineering. Currently, it is called jerk in English, secousse in French, ruck in German and smucitură in Romanian while in the United States it is known as "the snap of the whip". In the year 1936, only with four years before the strong earthquake that occurred in Romania, on November 10, 1940, the late Professor Aurel A. Beleș (1891-1976) (Fig. 1), published a paper about the role of jerk in dynamics [1]. Then in 1941, after the earthquake, in his quality of official expert for analyzing the collapse of Carlton Hotel in Bucharest, the same professor published two extended papers

Corresponding author: Ramiro Sofronie, Ph.D. professor emeritus, d.h.c., research field: structural and EQ engineering. together in a book entitled "The Earthquake and the Buildings" [2]. In that original scientific document an earthquake is defined as a succession of $\mathrm{j}$ random jerks, and the forces generated by some jerks are producing severe damages by dislocations [3]. The Russian Physicist Lev Landau (1908-1968), awarded with Nobel Prize in 1962, in his theory of dislocations explains that, as a rule, these damages are typically brittle. The action time of jerks is too short for developing deformations. Always the dislocations occur around local structural imperfections by high concentrations of stresses. Each construction material, elastic or non-elastic, has its own intrinsic time of dislocation when stresses are randomly redistributed. That time has to be compared with the jerk's time of action. Only then a right conclusion on the dynamic phenomenon of amplification could be correctly drawn. The book published by Aurel A. Beleș [2] was an event because that marked the beginning of Romanian Codes for Seismic Design and Protection. Now, in 2017, after 76 years, modern prescriptions inspired by the Eurocodes are in force. The paper further presents an updated level of knowledge on the seismic jerk, a simplified analysis method and two study cases. The paper concludes with some comments on the Principle of Plausibility as provided by ISO 13822:2010 after its extension on buildings of cultural heritage as a kind answer to the UNESCO-ICOMOS's Scientific 


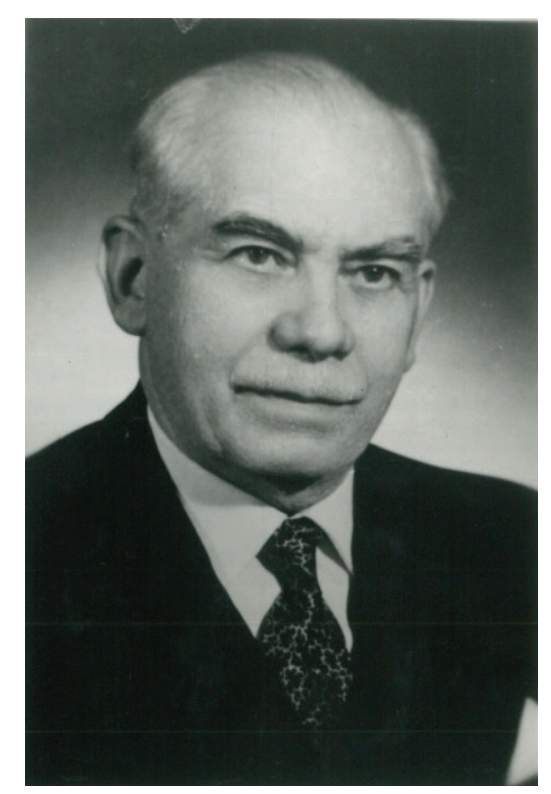

Fig. 1 Aurel A. Beleș.

Committee ISCARSAH special request.

\section{Analysis Method}

Generally, the seismic jerks occur in the case of buildings with unbalanced masses. For evaluating the seismic risk of these buildings the first Conservation Law of Mechanics is used, namely that of Linear Momentum [4]. Considering a building composed by two bodies, the lower body with the mass $m_{o}$, density $\rho_{o}$, volume $V_{o}$ and seismic velocity $v_{o}$ while the same parameters of the upper body are $m, \rho, V$, and $v$, respectively. The only unknown parameter from the eight ones above defined is the seismic velocity of the upper body $v$. In these conditions the expression of Linear Momentum for the upper body assumes the form

$$
m \vec{v}=\text { const. } \rightarrow m=\rho V
$$

Since the Linear Momentum of the lower body is known its constant value is introduced in the above first equation, and successively three equations result

$$
m \vec{v}=m_{o} \vec{v}_{o} \rightarrow \vec{v}=\frac{m_{o}}{m} \vec{v}_{o} \rightarrow \vec{v}=\frac{V_{o}}{V} \vec{v}_{o} \rightarrow \frac{V_{o}}{V}=\psi
$$

By the virtue of the Law of equality between the impulse of force and Linear Momentum one finally finds

$$
\vec{F} t=m \vec{v} \rightarrow \vec{F}=\frac{m \vec{v}}{t}
$$

This force of impulse acting in the gravity centre of the upper body is compared with its bearing capacity to pure shear. The duration of impulse is evaluating on the basis of available recordings from former earthquakes, the type of construction material and the desired degree of accuracy. Usually, for the first approximation that duration is located in the narrow interval of $\mathrm{t}=0.8-1.2 \mathrm{~s}$.

\section{Palace of the Former Society "Adriatica"-Trieste in Bucharest}

The building was designed by the famous architect Petre Antonescu and opened for service ninety-one years ago, in 1926 (Fig. 2). It has a RC spatial structure with two underground levels and eight levels over the ground. The ratio between building's depth and height assumes the optimal value 1:6. The plan of building has a single polygonal and closed contour, but with non-rectangular angles and without any axis of symmetry. In spite of this less usual geometry, imposed by the available space for construction at that time in down town, the building behaved well to the both strong earthquakes that occurred in the twenty century. As a palace the building was personalised by the architect with an elegant pergola consisting of 16 slender RC columns connected at their tops with an elliptical ring. One year ago, during a technical inspection it was observed that all RC columns were marked like bitten at their bases (Fig. 3). The bite is almost identical to all of them and it is not profound; mainly the plaster was broken and detached (Fig. 4). The layer of concrete for protection the steel reinforcement was neither broken nor removed. It became obvious that the phenomenon of dynamic amplification "snap of the whip" has occurred, and strong shearing forces were developed. The theoretical analysis was supported by a numerical model, and the results of site investigations were carried out by the Research Institute URBAN- INCERC in Bucharest. For instance, the period of oscillation in the fundamental 


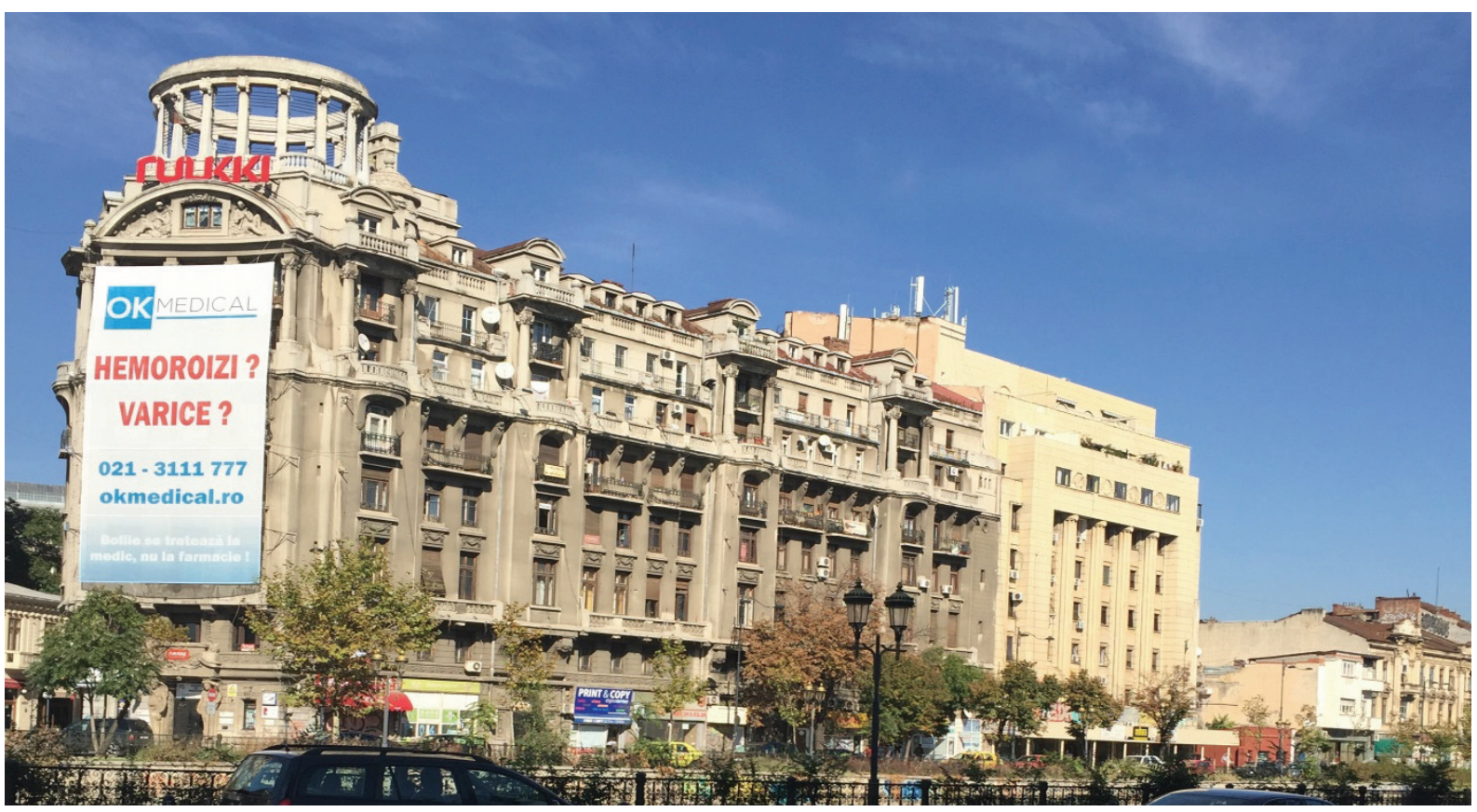

Fig. 2 Palace of the former society "Adriatica-Trieste" in Bucharest.

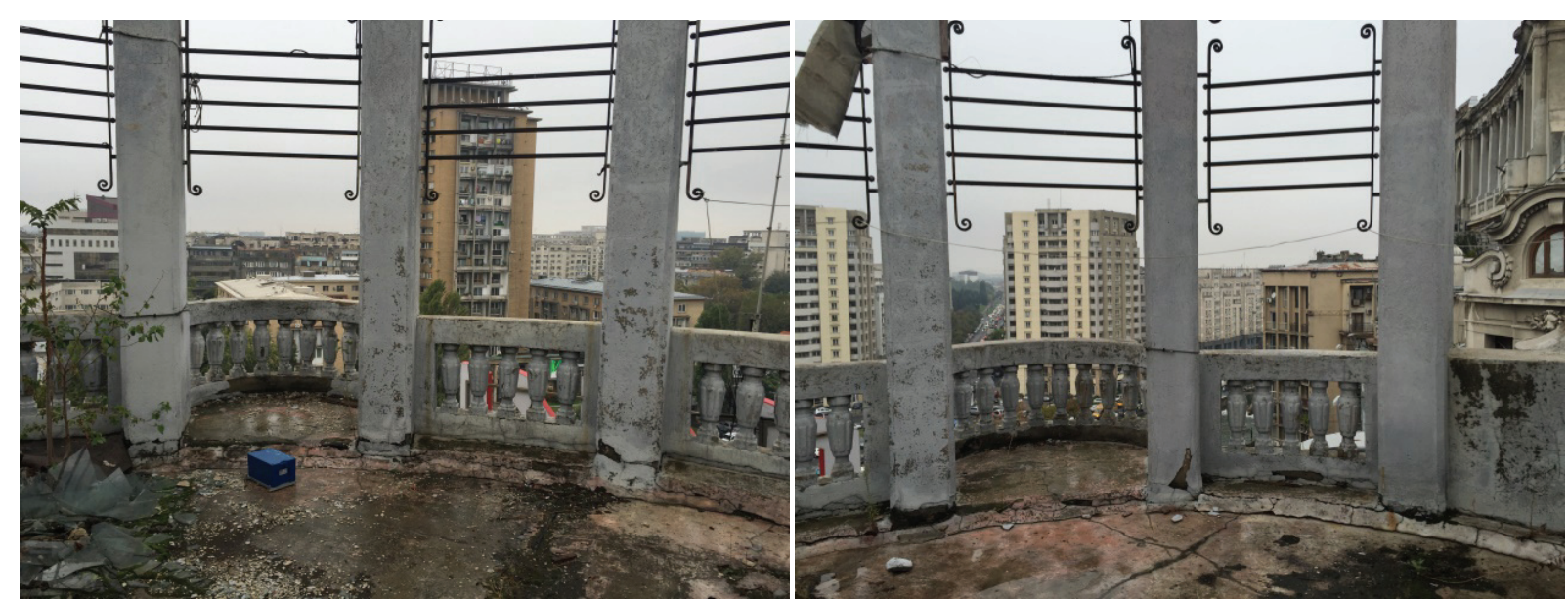

Fig. 3 Pergola's RC columns.

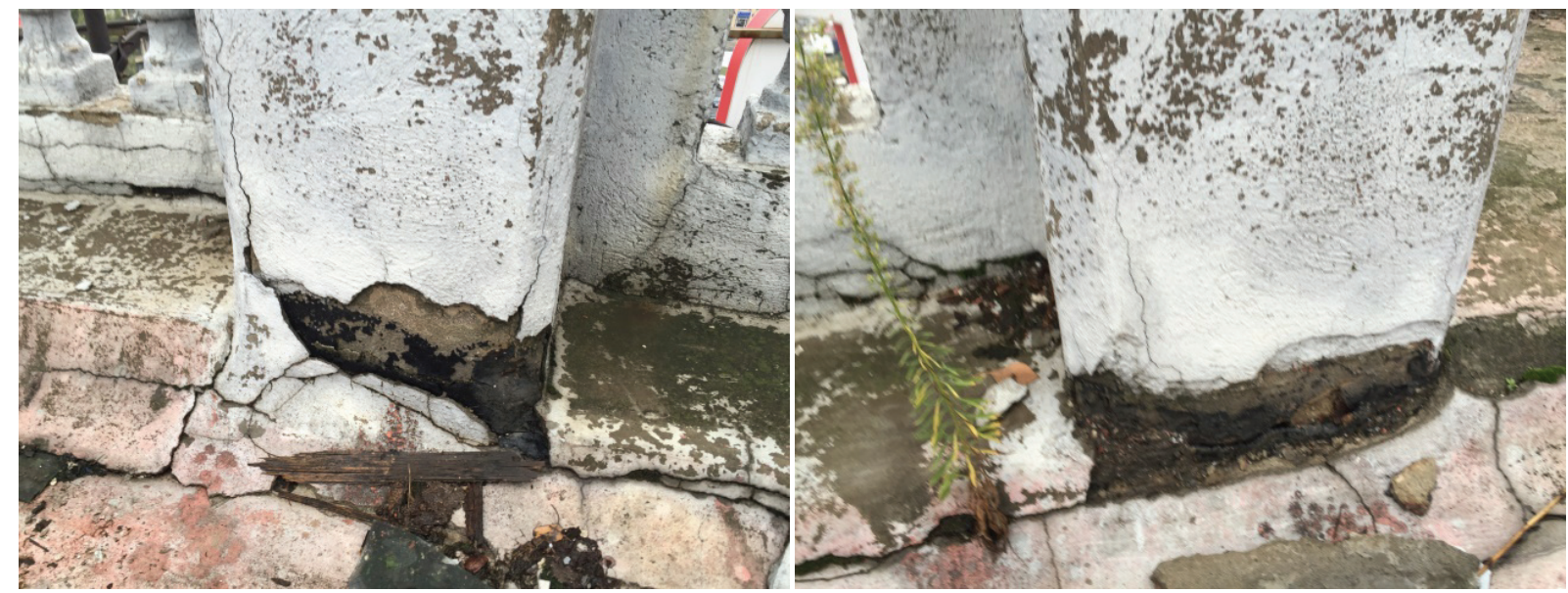

Fig. 4 Shear bites on the bases of RC columns. 


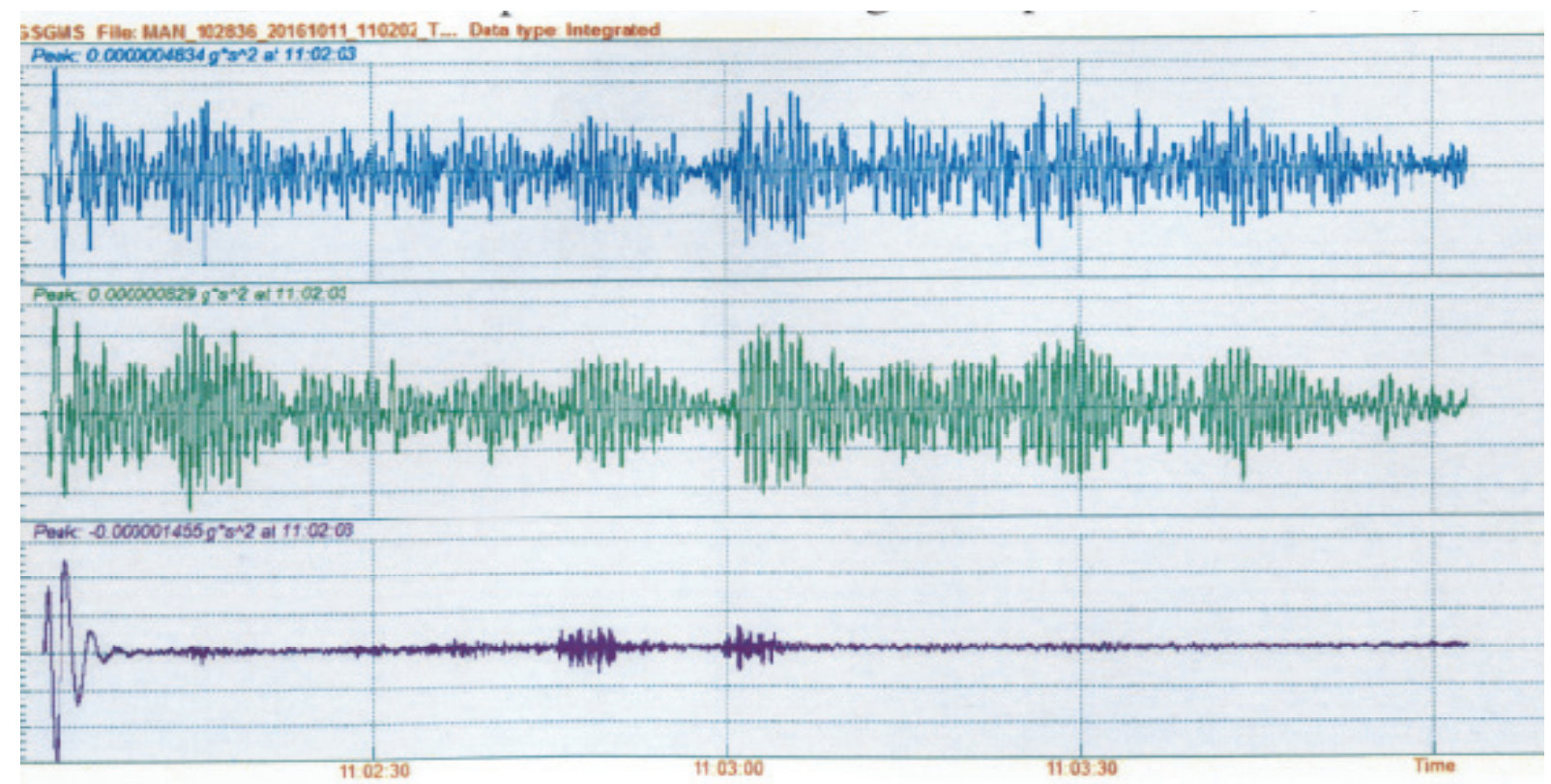

Fig. 5 Micro-seismic displacements of the building recorded on October 11th, 2016 by INCERC.

mode, according to the Code P100-1/2013, assumed the value $0.80 \mathrm{~s}$, and by measurements it was found $0.69 \mathrm{~s}$ (Fig. 5). This late value was used for calibration the numerical model. Further the analysis method above described was applied. It was used first the Eq. (5) where the lower and upper bodies, namely the building and its pergola, assume the values $V_{o}=24,256$ $\mathrm{m}^{3}$ and $V=246 \mathrm{~m}^{3}$. The ratio of the two volumes gives the amplification factor $\psi=98.6$, almost 100 . Therefore, along a height of $35 \mathrm{~m}$, from the ground level to the base one of pergola the velocity of seismic waves is amplified about hundred times. The velocity adopted in this case was taken over from the recordings made by INCERC Bucharest during the earthquake that occurred forty years ago, in 1977. It was the maximum value reached only once during that strong quake, namely $v_{o}=0.71 \mathrm{~m} / \mathrm{s}$. In these conditions, the velocity of seismic action at the base of pergola level assumes the value $v=98.6 \times 0.71=70 \mathrm{~m} / \mathrm{s}<v_{s}=340$ $\mathrm{m} / \mathrm{s}$, i.e. much lower than the velocity of sound in air. Therefore the quake action has not been accompanied by any noise from cracks or crashes in building structural or complementary members. Since the volume of RC in pergola structure is $V_{R C}=18 \mathrm{~m}^{3}$ from the above Eq. (7) the seismic impulse results $\mathrm{Ft}=m v=$
$2,500 \times 18 \times 70 \mathrm{t}=3.15 \mathrm{MNs}$. For a specific resistance to pure shear of $1.3 \mathrm{MPa}$, pergola's RC 16 columns, each with a cross section of $0.195 \mathrm{~m}^{2}$, the bearing capacity to shear assumes the value $\mathrm{F}_{\text {cap }}=0.8 \times 16 \times$ $0.195 \times 1.3=3.25 \mathrm{MN}$, where 0.8 is a reducing coefficient for non-uniformity. The force of seismic impulse assumes according to Eq. (8) the expression $\mathrm{F}$ $=3.15 / \mathrm{t}(\mathrm{MN})$ and may take the following values: $\mathrm{F}(\mathrm{t}=$ $0.8 \mathrm{~s})=3.94 \mathrm{MN}, \mathrm{F}(\mathrm{t}=1.0 \mathrm{~s})=3.15 \mathrm{MN}$ and $\mathrm{F}(\mathrm{t}=1.2$ $\mathrm{s})=2.63 \mathrm{MN}$. On the other side $\mathrm{F}_{\text {cap }}=3.25 \mathrm{MN}$ shows that for impulses shorter than $1.0 \mathrm{~s}$ the condition of strength is no longer satisfied. As it was mentioned above in introduction here that starts the discussion about the time if dislocation specific for each type of construction material.

\section{The Church of Antim Monastery}

The church was built in the style of three-lobed plan with enlarged pronaos in 1715 by Antim Ivireanul. The first church with this plan was erected in 1512 by Prince Neagoe Basarab in Curtea de Argesh. Since then other three similar churches were built, two in Bucharest, to Radu Voda and the actual Patriarchy, and the third to Hurez. In the case of the Antim Monastery Church the pronaos was unfortunately only partially 
enlarged (Figs. 6 and 7). This is why the church proved to be very sensibly to seismic actions. Indeed, in 1738 , after only 23 years from completion, under a strong earthquake both steeples collapsed and later were rebuilt. In 1865 the church was flooded by the waters of Dambovita River. Lately, by the strong earthquake in 1940 both steeples collapsed again and were rebuilt until 1948.

In the subsequent analysis of seismic response all parameters of church body are denoted with zero lower index, the eastern steeple with $\mathrm{E}$ and the western one with W. So according to the numerical model specially created for this church the volume of church body is $V_{\mathrm{o}}$ $=3,002 \mathrm{~m}^{3}$, the volume of the eastern steeple $V_{\mathrm{E}}=410$ $\mathrm{m}^{3}$ and that of western steeple $V_{\mathrm{W}}=350 \mathrm{~m}^{3}$. Now the following two amplification factors result: $\psi_{\mathrm{E}}=(3,002$ $+350) / 410=8.18$ and $\psi_{\mathrm{W}}=(3,002+410) / 350=9.75$.
Considering for the maximum velocity of seismic waves on ground level the value recorded during the quake in 1977, namely $v_{o}=0.71 \mathrm{~m} / \mathrm{s}$, then the velocities at the level of the two steeples are calculated $v_{\mathrm{E}}=8.18 \times 0.71=5.81 \mathrm{~m} / \mathrm{s}$ and $v_{\mathrm{W}}=9.75 \times 0.71=$ $6.92 \mathrm{~m} / \mathrm{s}$. Since the masses of the two steeples are $\mathrm{m}_{\mathrm{E}}=$ $250,600 \mathrm{~kg}$ and $\mathrm{m}_{\mathrm{W}}=343,600 \mathrm{~kg}$, the forces of corresponding to seismic impulses are $\mathrm{F}_{\mathrm{E}}=250,600 \times$ $5.81 / \mathrm{t}=1,455,986 / \mathrm{t}(\mathrm{kgm} / \mathrm{s})=1.46 / \mathrm{t}(\mathrm{MN})$ and $\mathrm{F}_{\mathrm{W}}=$ $343,600 \times 6.92 / \mathrm{t}=2.38 \mathrm{t}(\mathrm{MN})$. Since the bearing capacities to shear of the two steeples are $\mathrm{F}_{\text {Ecap }}=0.525$ $\mathrm{MN}$ and $\mathrm{F}_{\mathrm{Wcap}}=0.720 \mathrm{MN}$ the lower durations in safety of the seismic impulses are $t_{\mathrm{E}}=1.46 / 0.525=$ $2.78 \mathrm{~s}$ and $\mathrm{t}_{\mathrm{W}}=2.38 / 0.720=3.10 \mathrm{~s}$. Obviously, the two durations are rather high for a seismic impulse and therefore structural interventions for reinforcing the two steeples are necessary.

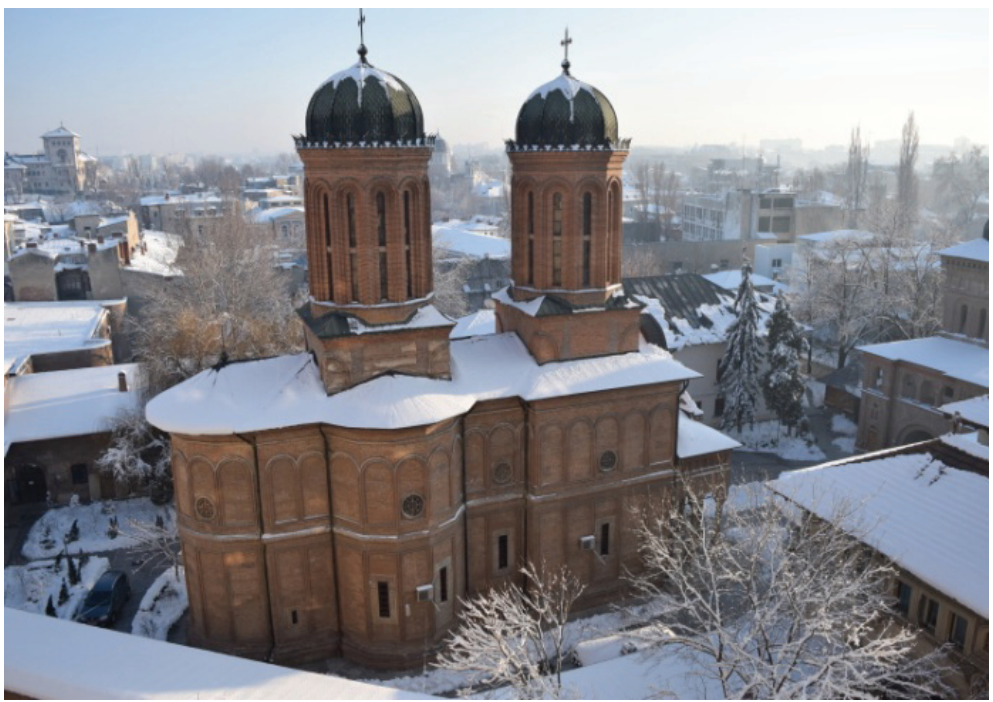

Fig. 6 Overview of the Church of Antim Monastery.

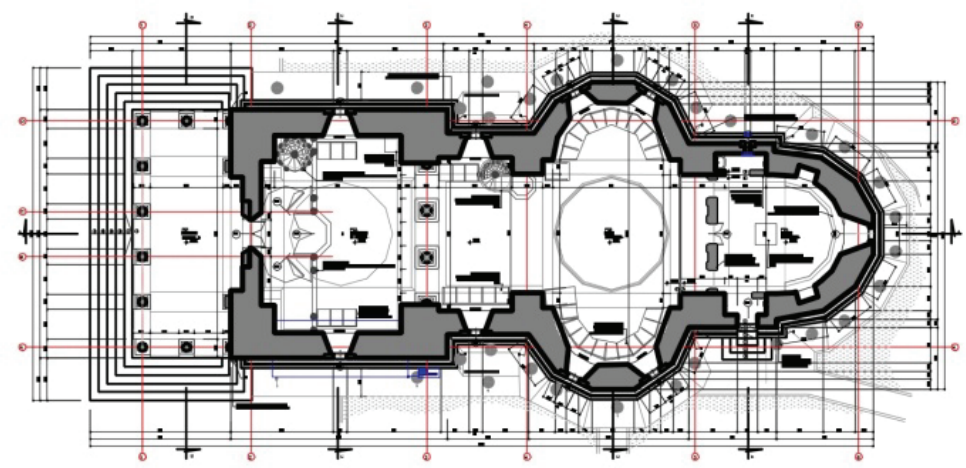

Fig. 7 The three-lobed plan of the Church. 


\section{Conclusion}

The analysis method proposed by paper for checking the unbalanced bodies supported by buildings is simple and can be easily applied to any desired degree of accuracy. The method is based on the first Law of Conservation in Mechanics and perfectly suited for such kind of quick acting actions like the seismic jerks. The two study cases presented have shown that the analysis method allows checking either the bearing capacity to shear of the structural members or the acting time of impulse forces. In both cases appearing the parameters that could be involved in the solutions of intervention aiming to improve the seismic response. According to the experience gathered during the years, in the field of rehabilitation works the intervention solutions are often disputed. This is why ISO 13822:2001, completed in 2010, introduced a clause of plausibility providing that "the one who pay decides". Usually the entitled person decides to ask for quick, additional proofs in order to support the intervention preferred. The analysis method proposed by the paper is flexible enough and allows studying different alternatives of interventions in order to simultaneously satisfy the expectations of both, the owner and the contractor.

\section{Acknowledgement}

The support in carrying out the numerical modelling of the two study cases by the Design Company "Structural Engineering Technology" in Bucharest, directed by Mr. Radu Cazamir and Alexandru Neacsu with the kind contribution of Mr. Liviu Gruia, all three MCE, is gratefully acknowledged.

\section{References}

[1] Beles A. Aurel. 1936. La notion de secousse et son rôle dans le dynamique. Bul. Math.-Phys.de l'École Polytechnique de Bucarest, 1936-1937, VII, 1, 2, 3, Fasc. 22, 23, 24.

[2] Beles A. Aurel. 1941. Cutremurul si constructiile Bul. Soc. Politecnice, LV, 10, 11.

[3] Landau, L., and Lifchitz, E. 1967. Théorie de L'Élasticité. Moscou: Éditions Mir.

[4] Landau, L., and Lifchitz, E. 1966. Mécanique. Moscou: Éditions Mir. 